Virginia LoCastro* \& Mayumi Masuko*

\title{
Plagiarism and Academic Writing of Learners of English 1
}

\begin{abstract}
Incidents and anecdotal evidence accrue of learners' resorting to plagiarism in their essays and research papers. There seem to be three possible reasons that plagiarism is common among students writing in English as a second language. First is the desire to cut corners. Second, there are differences in cultural practices. Third, the learners have a lack of skills and/or language proficiency. We wanted to begin to document the actual situation in Japan. Therefore, we decided to conduct an ethnographic type of study in which we would seek evidence from a variety of sources. Although we focused our attention on written assignments of learners within the classroom context, specifically examining plagiarising the work of others, we also examine the broader social context.
\end{abstract}

\section{Introduction}

Incidents and anecdotal evidence accrue of learners' resorting to plagiarism in their essays and research papers. Applebome (1997) reports on term papers for sale flooding the net. Howard (1995), in order presumably to cope with the ubquitiousness of plagiarism in academic writing programs in U.S. universities, makes a case for taking a positive perspective on such techniques as "patchwriting" by novice writers. One of us acted as a tutor at a major university in the United Kingdom where an estimated $90 \%$ of the essays written by three students were plagiarized. A writing class at a Japanese university and one in Slovakia could not function unless the students did the writing in class, as most would copy from each other if work was assigned for homework.

1 This paper is a revised version of a talk presented at TESOL'97, 11-18 March 1997, Orlando, Florida. We wish to thank Ann Chenoweth for her feedback on an earlier version.

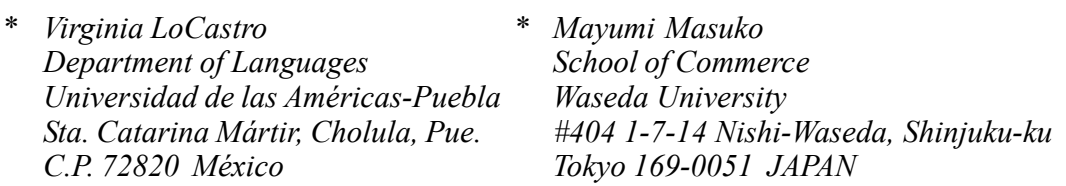

Hermes, Journal of Linguistics no. 28-2002 


\section{2}

Given the anecdotal evidence and our personal experiences, there seem to be three possible reasons that plagiarism is common among students writing in English as a second language. First is the desire to cut corners, as with NS plagiarism (i.e. they know it is wrong but think/hope no one will notice). Second, there are differences in cultural practices, in attitudes, and in training (i.e they could avoid it, but believe that it is acceptable to plagiarise). Third, the learners have a lack of skills and/or language proficiency (whatever they think, they can't do anything else).

Initial impetus for this project derives from Scollon's (1995a) call for research into the academic citation practices of learners in TESOL contexts which would take into consideration the broader cultural environment. We wanted to begin to document the actual situation in Japan with the aim of working towards improvements in writing instruction so that a larger number of the English as foreign learners (EFL) learners would achieve their professional goals. Therefore, we decided to conduct an ethnographic type of study in which we would seek evidence from a variety of sources. Although we decided to focus our attention on written assignments of learners within the classroom context, specifically focusing on plagiarizing the work of others, we examine the broader social context so that we can understand the problems of helping EFL learners develop academic writing skills.

The literature on plagiarism of L1 learners is quite extensive (REFS). There have been studies on the patterns of plagiarism found in Chinese learners of English writing (see, for example, Matalene, 1985; Bloch and Chi, 1995), but fewer which examine this issue in the context of Japan and the writing of Japanese learners of English. Previous investigations, such as Scollon's (1995a, 1995b) intellectual-history interpretation and Pennycook's (1996) educational-effects perspective, place strong emphasis on the Chinese learners' transferring practices from their L1 culture regarding views of originality, knowledge, and communication into their L2 tasks. However, our intuitions are that this is not the only factor in Japan. Our aim is to confirm the anecdotal evidence with an ethnographic investigation to explore to what extent a cultural interpretation would be the best explanation of the learners' behavior.

In this paper, first of all, we briefly review some relevant studies on the problem of plagiarism by learners of English. We follow with a description of our study, of the sources of information we utilized in the 
collection of evidence of learners' behavior with regards to plagiarism and our collection of learners' accounts about the subject of plagiarism. Next, we provide a brief overview of the pre-university educational system experienced by the learners. This section seeks to explain and offer interpretations of the findings. Finally, we discuss pedagogical implications which follow from our findings.

\section{Recent Studies}

Plagiarism, that is, the use without attribution of the language and/or ideas of a source text, is, needless to say, not an issue exclusive to NNS learners of English in academic papers. Writers of academic papers in general are expected to demonstrate the ability to integrate information from multiple sources and use the conventions of such a genre to acknowledge the authors of the source texts. Our survey of relevant sources is limited to those concerned with L2 writing and only to those published since 1990 . The audience we address is L2 writing teachers concerned about changing their classroom practices to help the students develop their writing skills and avoid plagiarism. First, we summarize some contributions from the cultural/ideological perspective; then we cite some studies in a more narrowly educational and developmental frame.

Scollon (1995a) suggests an ethnographic perspective, citing the need to go beyond the classroom to explore possible ideological explanations. In an earlier paper, Scollon (1994) raises the issue of "responsibility for the presentation of facts" (p. 36) vis-a-vis the NNS learner's perceived concern for the facts rather than "who might have originally stated them" (p. 38, his emphasis). The suggested explanation is the possibility that L1 writing practices may have an influence on signaling agency. Drawing from a variety of sources to discuss voice, face, "private authorial self" and responsibility in the context of a sociocultural tradition which prioritizes groups over individuals, Scollon calls for an understanding of ideological positions which differ from that underlying western-influenced writing conventions.

The theme of cross-cultural differences, specifically ideological positions with regard to authorship, responsibility for evidence, and attribution of agency is a major one, perhaps the most dominant, in the literature. Hinkel (1995) as well compares NS and NNS evaluations of four English essays written by NSs and by NNSs learners; her results 


\section{4}

indicate large cultural differences in the evaluations concerning such features as purpose, audience, clarity, and support for arguments. However, there are other possible explanations for features of second language writing cited by researchers.

Pennycook (1996) examines notions of "text, ownership, memory, and plagiarism" (p. 201) in the Chinese context, taking a sociohistoricaleducational view of the problem. His conclusions call for acknowledgment of the need to adhere to standards with regards to borrowing language and /or ideas without attribution, and, at the same time, reassessment of how TEFL teachers view "supposed plagiarism," which, in his view, is "pedagogically unsound and intellectually arrogant" (p. 227).

Leki and Carson (1997:51) discuss the difficulty of distinguishing between intertextuality and plagiarism as a possible limitation of English for academic purposes (EAP) students when asked to write from sources. Students mentioned that the problem with using a source text was that they regarded certain words, sentence structures, organizational patterns, or even ideas as used up once the text employed them, making them unavailable for use by the students themselves. Perhaps the learners resort to plagiarizing out of frustration, feeling there is little left to be created by them. Further, with regards to writing paraphrases and summaries in discipline-specific writing, the learners in their study felt such forms called for them to write beyond their proficiency level, indicating that here again, it is a question of a lack of the necessary skills.

Related to general writing skills is the knowledge and ability to write genre-specific texts. Bloch and Chi (1995) suggest plagiarism might be viewed as a "compensatory strategy" (p. 238), utilized by both NS and NNS writers, particularly where there are pressures to conform to conventions the writer may not yet have mastered. Taylor and Chen (1991) contrast texts written by three groups of physics scientists, Americans writing in English, Chinese writing in English, and Chinese writing in Chinese, concluding that much of the variation in the introductions to the papers results from the discipline rather than cross-cultural differences. The genre of scientific writing may be as important in characterizing text variation as culturally-influenced rhetorical styles.

Taking more of a developmental perspective is the report by Campbell (1990), who discusses stages where learners engage in "degrees of copying" from the source texts. Her study documents the use of a reading 
text as a source for academic writing, where few of the students acknowledged the author of the text. She concludes that language proficiency is an important factor in the ability of the learners to use the source text appropriately. Connor and Kramer (1995) also investigate the ability to write from sources, utilizing essays of students of business administration. On the basis of their study, they contend that language proficiency as well as constraints due to cultural and earlier educational practices may affect the learners' ability to write academic papers.

In the context of learners' skills is the issue of lack of or inadequate training in academic writing. Braine's (1995) study of "Writing in the Natural Sciences and Engineering" addressed the problem of application to the classroom head on by stating "English teachers should have a better understanding of academic writing in order to teach it" (p. 113), a view with echoes found in Leki and Carson (1997) and Campbell (1990). Specifically, Braine suggests a genre approach to the teaching of writing so that learners in different disciplines develop an understanding and ability to use the discourse conventions of their major fields. Braine's contribution is important as presumably with greater knowledge and self-confidence, L2 writers would avoid plagiarism.

Finally, Smith (1997) zeroes in on the gate keeping functions of academics, of which handling plagiarism by students is one, and raises the question of the role and responsibilities of teachers with regards to students' goals in the U.S. academic context and beyond. Writing courses which focus exclusively on creative writing and personal anecdotal essays may be viewed by the students as infantilizing, disempowering them for the future careers, and may not prepare them for more academic styles of writing. Hinkel (2000) argues for explicit instruction in ESL classes of the kind of writing many of the learners will be expected to do once they enter mainstream programs in their majors, particularly in M.A. and doctoral programs.

A cultural interpretation of the act of plagiarism may be the most plausible as the over-riding heuristic frame, subsuming the educational system under it as just one, perhaps the most important, of the sites for the playing out of a culture's values and beliefs. Research on curriculum design (for example, Clark, 1987) highlights the important role of values in educational systems throughout the world. The way a writer or a speaker handles the use of multiple sources of information to create text 
or discourse involves culturally-constrained notions of authority, entitlement, ownership, responsibility for information and evidence. The academic conventions developed historically within western contexts represent an ideological position, which may be at odds with the perspective of a non-western nation regarding, for example, the importance of developing the writer's voice in texts.

In this brief review of literature, the following explanations - not mutually exclusive - are apparent: cultural-ideological differences; problems with writing skills; developmental processes; and training either none or inadequate -; and the role of academic gatekeepers. We now turn to an exploration of the sociocultural-educational context of Japanese EFL writers.

\section{Our Study}

For this study, we collected information from three sources: (1) senior theses, in English and in Japanese, (2) other papers written by learners, specifically summary-reaction papers, and (3) input from learners in the form of responses to a questionnaire and informal interviews conducted during office visits. Due to the complexity of the problem of plagiarism, we used a hybrid, multifaceted approach to data collection.

\subsection{Senior Theses written in Japanese}

Concerning the senior theses (i.e papers of about 7,500 words, written by students in the final year of a four-year BA course) written in Japanese and included for the purposes of comparison, generally it is not clear which part is the student's own ideas and opinions and which consists of paraphrases, summaries, or unattributed direct quotations from outside sources. The student may state that a particular theory, framework, or source will be used, even naming the author; however, no source is actually cited and it is not transparent to the reader what is directly copied, what is paraphrased, and what are the student's comments.

Fortunately for the investigator, Japanese students' own style is usually very different from that of their sources. We were thus able to estimate which sections were copied and which original with a considerable accuracy. 
Two senior theses were examined by counting pages or lines on pages. In the first one, it is estimated that more than half of the pages were composed entirely of unattributed quotations or paraphrases, while only an eighth of them contained text which could be considered to be original to the student. The remaining pages consisted of roughly equal proportions of unattributed quotes or paraphrases and text that appeared to be the student's original writing. In sum, it appears that approximately $70 \%$ of this senior thesis was "copied." In the second case, a little over a third of the text appeared to be copied. These two texts represent the typical range.

\begin{tabular}{|l|r|r|l|l|r|}
\hline & $\begin{array}{c}\text { Whole pages } \\
(\%) \\
\text { 'Copied' }\end{array}$ & $\begin{array}{c}\text { Whole pages } \\
(\%) \\
\text { 'Original' }\end{array}$ & $\begin{array}{l}\text { Estimated } \\
\text { page parts (\%) } \\
\text { 'Copied' }\end{array}$ & $\begin{array}{l}\text { Estimated } \\
\text { page parts (\%) } \\
\text { 'Original }\end{array}$ & $\begin{array}{c}\text { Total } \\
\text { number } \\
\text { of pages }\end{array}$ \\
\hline Thesis 1 & $26(55.3)$ & $6(12.8)$ & $6.5(13.8)$ & $8.7(18.5)$ & 47 \\
\hline Thesis 2 & $14(30.8 \%)$ & $25(54.9)$ & $2.5(5.5)$ & $4.5(9.9)$ & 46 \\
\hline
\end{tabular}

Table 1 Copying in two Japanese senior theses.

\subsection{Senior Theses written in English}

The first of the two senior theses written in English was by a student who had had most of her secondary education in English-medium international schools abroad (Singapore and Australia). An examination of her thesis brought to light the following. First of all, she had included a bibliography, but no reference list, making it impossible to identify the cited works. Secondly, she had cited only what she directly quoted. Thirdly, no sources were given for entire chapters of content on phonological, syntactic borrowings from American into Australian English, nor for the framework she had adopted for her thesis. It was possible to discuss her writing with her and, while she was cooperative in rewriting the thesis to make it conform more to standard academic practices, she maintained that she had not been taught that what she had done would be unacceptable.

In the second senior thesis written in English, the student had interwoven entire paragraphs and sentences copied from the original sources with a small number of his own. In this case, an interview with him resulted in 


\section{8}

his admitting that he had plagiarized due to time pressures on him to complete his thesis. Spack (1997) found that Japanese students in her classes gave the same explanation. In rewriting, this subject substituted direct quotations for copied passages; however, he did not make efforts to paraphrase and then attribute the source of the ideas to the original author in other parts of this thesis.

\subsection{Other English Papers}

Other academic papers written in the foreign language were collected to obtain more evidence as to what learners do with their writing assignments. In the case of one assignment to write a summary/reaction paper on a journal article, of 30 assignments turned into the teacher, 16 were massively copied from the original articles. The students had been allowed to choose an article in a scholarly journal (e.g. from the Journal of Pragmatics) which they would then use as a source for their final, data-based paper at the end of the term. The pattern found in the assignments was that the student wrote an introduction and sometimes a reaction section in which they included their own ideas or personal accounts related to the topic of the article. However, some only provided an introduction, taking the reaction section from the conclusion of the original. The body of the paper was copied from the original article.

In sum, we observed the following characteristics of plagiarism in these students' writing:

(1) sources are given only when directly quoting from a source, if then;

(2) no reporting verbs are used when paraphrasing or summarizing from a source, nor is there attribution to the original author;

(3) the original text is reworked, with phrases, parts of sentences, lexis "copied," sometimes with tell-tale "mistakes" of Japanese learners added, such as dropping all the definite articles; and

(4) the first and final paragraph(s) are the student's with the entire body of the essay taken from the original

Here is an example of the first characteristic:

These examples may have helped to restore Australia's confidence in its linguistic identity, and indeed, there were optimistic views that Australia.... As Dinning observed in The American Scene (1939), ...to use American slang - that very lively and expressive medium - is not to 
become Americanized....We all use that argot...England uses American slang and England is in no danger of Americanization."

As is clearly evident in this case, the student only gave the attribution for the direct quote, neglecting to provide the page number and giving only the date of publication.

An example illustrating both the first and second features is as follows:

The first thing the infant must acquire is the concept of the self. Gender identity, the conception of self that one is female or male, is developed during the first few years of life. Before the age of three, children have little conception of sex roles. At the age of three to five, sex roles appears to be developing. From the age of five to seven, children achieve gender consistency, "the tendency to see oneself consistency as a male or female" (Pearson 38). ${ }^{2}$

Other than providing an attribution for the direct quotation, the writer gives no indication that the paragraph is a summary of a page of an introductory textbook on gender development.

The next incorporates examples of the third and fourth characteristics. Here is the first paragraph from a research paper:

The reason why I chose to do my paper on metaphors was because metaphors make you think, in a new way, about the landscape we use. We use it everyday both when we talk and write. Metaphors are a part of everyday speech that affect the way in which we perceive, think and act. I did some research on metaphors and came up with different types of metaphors which interested me. And I took some metaphors from a magazine and analyzed them in this paper.

It is not difficult to find clues that this was written by a NNS learner of English: the pronoun use and the very basic vocabulary, as well as syntactic awkwardness. Now, the following is the student's second paragraph and the original text, Lakoff and Johnson's Metaphors We Live By (1980), which was only mentioned by the student when examples were cited.

\section{Student}

Metaphor is for most people is viewed as characteristics of language, a device of the poetic imagination. It is pervasive in everyday life, not just in language but in thought and action.

2 We are not able to provide the full reference for Pearson, cited in the student's paper. 


\begin{abstract}
Original
Metaphor is for most people a device of the poetic imagination and the rhetorical flourish - a matter of extraordinary rather than ordinary language. Moreover, metaphor is typically viewed as characteristic of language alone, a matter of words rather than thought or action. We have found, on the contrary, that metaphor is pervasive in everyday life, not just in language but in thought and action.
\end{abstract}

The student's paper continued for ten pages, almost all of it taken in this fashion from the Lakoff and Johnson book. It is striking and significant that a well-known book was used rather than a more obscure one which a teacher might not have read ${ }^{3}$.

\title{
3.4. Interviews
}

We asked the writers of the texts we examined to give reasons for their behavior. Most of them admitted that they had copied from the original source, giving such reasons as lack of time, not knowing how to do the assignment, and fear of getting a poor grade due to their English proficiency level. Some, however, did challenge us when confronted by our suspicion that they had plagiarized, denying their behavior at first. They appeared to be shocked that we had noticed that there was a clear gap between their own writing and speaking abilities and the writing of a native speaker of English, evident in the assignment they had turned in. In some cases, there is also an obvious gap between the intellectual level of the thoughts expressed in the writing in the plagiarized text and the undergraduate students' perceived capacity in the subject area, which caused discomfort on the part of the student.

\subsection{Questionnaire Results}

In order to collect information about the learners' attitudes and experiences with plagiarism, we developed a questionnaire (see Appendix A), drawing ideas for items from Pennycook and our own experiences in the Japanese university context. Due to the contentious nature of this subject of inquiry and the delicacy of the issue, we were only able to collect responses

\footnotetext{
3 Chenoweth reports that, in her experience, students have explained that they did not cite the famous book, assuming the teacher would know it already; she notes: "Is this just a case of the students trying to flatter their teacher out of a sticky situation?"
} 
from 37 students. We explained the purpose of the survey to the informants, specifically that we would be using our findings to make suggestions to the English Language Program for revisions to the writing curriculum. While the results cannot be generalized beyond this situation, we feel they are, nevertheless, representative enough to support further research.

\subsection{Student Profile 4}

During regular class time, we collected questionnaire responses from 37 students who were taking content courses in the Languages Division and Natural Sciences Division (see Appendix for details) Some twothirds were women, about a third had experience living abroad, and most of them claimed to have had some training in academic writing in English.

When asked if they had plagiarized, more than half said that they had done so sometimes or often (Table 2). However, only three students wrote that they had been caught plagiarizing (Table 3 ). One of them had been told to rewrite her paper and the other was warned not to plagiarize again. The third claimed that no sanctions were imposed.

The first part of the questionnaire concerns students' attitudes toward academic writing in English. Students were given a number of statements and asked to choose those which fitted their own feelings about academic writing; the total number of responses thus far exceeds 37 (Table 4). The most popular answer was that having to write papers in English was "useful training for their future career or work", indicating that students may appreciate the training. At the same time, more than half answered that writing academic papers was "necessary to fulfill graduation requirements", suggesting that students might not enjoy writing or they might not think it is useful. About half chose"Writing in such a style is only required in courses done in English", which also implies that some students might consider academic writing a uniquely Western concern that is irrelevant or unnecessary in Japanese.

A similar proportion indicated that they "want to learn how to write well in Japanese" suggesting that they perceived a need for instruction

\footnotetext{
4 All comments about the courses taken by the informants refer to the academic program of International Christian University and to its English Language Program in Mitaka, Tokyo, Japan.
} 


\section{2}

in Japanese classes to be changed. This is related to the answer to a later question that they plagiarized in "courses which require papers in Japanese". These answers may appear irrelevant to the issue of academic writing in English. However, they point to important factors that we believe may have contributed to the current situation in English classroom. That is, lack of training in academic writing in Japanese may have resulted in students' indifference to plagiarism. We shall come back to this point shortly. In this context it is striking that a third of students agreed that it was 'interesting to learn a different way of thinking', which implies that writing in English is culturally alien and hence the skills are not necessarily transferable.

The questionnaire also included a section where students were requested to write in their own words how they felt about plagiarism. About three-quarters of the students wrote comments, and, generally speaking, students who had plagiarized tended to give excuses or rationalizing comments about their own and others' behavior while students who had never plagiarized were more likely to be negative toward plagiarism. There are some exceptions to this generalization, and some of the students' comments are examined in this section. There were more comments from the Languages Division students, possibility for two reasons: both researchers were from that division and it is the Language division where the learners were made aware of plagiarism.

Firstly, here are some comments that fit the generalization. A thirdyear male student in the Natural Sciences Division, who stated he had plagiarized often wrote: "If I totally agree to opinions of some articles, it's hard for me to make an academic essay on the topic". The student justifies his behavior by claiming that it does not seem necessary to indicate sources of information which coincide with his opinion. A third-year female student in the Division of Education who had plagiarized sometimes stated, "To some extent, non-English natives have to imitate the way of writing in a text but must not just copy a whole of it!" She attributes her action to not being a native speaker of English. Her rationalization implies that students might not be receiving sufficient instruction as to why they should not plagiarize and how they could avoid plagiarism by paraphrasing, summarizing and explicating the source of information.

A fourth-year female student in Natural Sciences who had plagiarized sometimes postulated that indifference to plagiarism is widely found among 
Japanese. She wrote: "In Japan, people are not generally aware of plagiarism. It seems that people believe it is OK not to cite sources and just copy down a passage in essays written for university course. So it is good that students are informed of plagiarism at ICU". However, her own behavior does not reflect what she presumably had been told.

Similar comments were made by others, suggesting that the content of Japanese classes up to university currently does not provide instruction in Western-style academic writing. This view is backed by a third-year female student in the Division of Natural Sciences who had never plagiarized. She confesses that "I'm not sure the border of plagiarism and not plagiarism. And I think for us Japanese the definition of that is difficult and not understanding."

As stated above, students who had not plagiarized were critical of others who had done so. This is a typical response from a third-year male student in the Languages Division who had never plagiarized: "I don't want to do it, because if someone ask about what you stated as you wrote, you can't explain it. Besides, I want my idea, original on my paper". This comment may reflect acculturation to American/western ideas about originality.

Some of the students who never plagiarized, however, blame teachers. For instance, a third year female student in the Languages Division who had attended an international school and who had never plagiarized wrote:

I do think that there are many professors at ICU who don't really read our essays carefully enough, especially professors who teaches large classes like General Education. It does bother me, to think some professors do not read it carefully when you put an effort on your paper and those who do plagiarize (consciously or unconsciously) get away with it anyway [the emphasis original].

Similarly, a second-year female student in the same Division contended that

Teachers should be able to detect whether or not the students plagiarized or not. I've seen a lot of students plagiarizing at ICU. It is doubtful that the students have understood the reading and it is just a waste of time if students had not understood the reading.

A fourth-year female student in the Natural Sciences who had never plagiarized criticized teachers but for a slightly different reason. 
When I was in the first year, it was difficult to write an essay by the deadline without plagiarizing. Even outside the ELP, I copied passages from books when I wrote essays but that was because I hadn't realized that it was better to summarize and/or write my own ideas. Ever since I understood the importance of writing my own ideas, I have stopped copying sentences without reference" [original in Japanese].

Students' comments cited above thus can be classified into two types. One is 'excuses'. Students claim that they plagiarized because (a) as non-native speakers, their ability in English was not sufficient for them to paraphrase or summarize others' ideas and/or (b) as Japanese, they were not aware of what plagiarism is, why it is (seen as) bad (in western culture), or how plagiarism could be avoided. The other consists of "accusations" or "reproach"; students felt that they were not the only guilty party. Teachers also were responsible as (c) they did not give students enough time to write essays and the students had to resort to copying other people's writing; or (d) they had not taught students about the negative view of plagiarism; or, even worse, (e) they did not recognize plagiarism when they saw it, thus inadvertently inviting students to plagiarize as it would go unpunished.

In sum, the learner interview and questionnaire data confirm the categories found in the literature as to the causes of plagiarism: socioculturalideology differences, L2 language proficiency, and poor training. In addition, two more categories can be added: time pressures despite knowledge of what should be done and then the lack of a strong role on the part of the teachers in checking for plagiarism.

\section{Cultural and Educational Background}

In this section, we discuss relevant contextual factors which comprise the background against which even the most motivated learners are forced to operate to develop their writing skills. First, we describe the training in the primary school mother-tongue classes followed by brief comments on the teaching of writing in English language classes. We then discuss the effects of the educational practices to which the learners are exposed.

First of all, according to Sasaki (1997), in mother tongue (kokugo, i.e. the "national language") classes, Japanese learners are generally not taught to write essays of an American or western type in their first language. Three types of writing are addressed: (1) logical type sentences, 
(2) literary type sentences, (3) reaction statements. Of the three types, (3) is the most frequently taught and (1) the least. With the first, what might be labeled "expository" or "objective" writing, the propositional content is the focus and learners are expected to paraphrase the sentences of the source text, the purpose being to check that they have understood the content correctly and completely. Note the tasks may be oral or written. Agency - the source of the ideas - is not marked, perhaps because it is clear, from the context of situation, to the teachers and the students that are co-present who the original author is.

With the second, literary type of written discourse, the pupils are asked to do two different things. Again, they are expected to paraphrase what an author has written, to show comprehension; however, in this case, a reporting verb is required which is considered to function as a subjective opinion marker, typically to omou., "(I) think (that)..." The third type of task, giving a reaction statement, is the time for the pupils to indicate their own opinions about what the author wrote, which also requires a subjective opinion marker, typically $\sim$ to omou. (LoCastro and Netsu, 1997).

Hai to, boku wa, juusu no kan ya, gyunyuu pakku wo, risaikuru tte yuu mitaina koto de, risaikuru sureba, gomi wo heraseru kara, seikattsu no naka no, gomi mo, sukoshi wa hette, kukara ii to omoimasu.

Yes, ah I, about things like recycling juice cans and milk cartons, if we recycle [these things], [the amount of] garbage can be reduced and there will be less and less garbage in our life and that is good.

The utterance is a mixture of statements of the vice principal, giving a talk about recycling, and the pupil's own thoughts. They are mixed and marked by the same linguistic form, $\sim$ to omou, whether the pupils are restating the contribution of another person, i.e. the principal, or giving their own views on the topic. In other subject classes, such as social studies, students' opinions and interpretations are also sought. In none of the classrooms does the teacher critically evaluate students' contributions. The explicit purpose of such structuring of classroom discourse is to socialize them about the value of listening to their classmates and the use of formulaic hedging routines, such as $\sim$ to omoimasu, in particular those involving the reporting of the talk or writing of others. LoCastro and Netsu (1997) note that this culturally influenced language usage may have a role in the tendency of Japanese writers and speakers of English 
26

to ellipt agency as the focus is on not only the propositional content but also the need to do facework and linguistic politeness.

\section{EFL in Secondary Education}

Not only, however, are the learners not taught how to write extended texts in their mother tongue, the efforts to develop their writing skills within the context of EFL classes in junior and senior high schools do not provide more appropriate training for future academic work. The genres of writing which can be found in recent Ministry of Education-approved writing textbooks for high schools tend to be highly personal, in the hereand-now, characterized by the use of the second person personal pronoun "you." In the textbooks, there are introductions, family life anecdotes, expression of personal likes and dislikes, dialogues, journals, letters to pen pals, didactic advice on how to meet a girl, how to avoid AIDS, and cross-cultural difference anecdotes. The main aim of the materials is to learn and practice grammatical patterns. Out of 28 lessons in one book (New Horizon, 1994), only the last could be characterized as "objective" writing style. Clearly, there is a problem of a lack of appropriate models and exposure to the type of writing the students will be exposed to in an academic environment.

Whatever their role in the development of literacy in Japanese, the effect of these educational practices is problematic from the point of view of later English as a Foreign Language academic skills classes at university level, for several reasons. First, the relative lack of evaluation in the mother tongue primary school classes of what is in a text does not correlate with critical thinking or literacy skills development. Further, a paraphrase of a sentence with the subjective opinion discourse marker obfuscates agency, and thus attribution of sources is problematized. There is more emphasis on teaching the learners to give their own reactions, rather than their clearly indicating the source of the ideas being restated. In our view, the teacher's non-interventionist role in the context of the mother tongue classes does not serve to move the learners beyond their current level of development and knowledge. The teacher is focusing on culturally appropriate language socialization (see Anderson, 1995).

Second, in addition, if one seeks further understanding of the context outside the classroom, one can observe that there is a lack of what Westerners would regard as models of rigorous academic writing in 
Japanese. The types of reading materials students read in Japanese do not cite sources or provide references, at least not in any consistent manner. According to the managing editor of the Japanese edition, the prestigious journal Foreign Affairs has submissions illustrating "sloppy scholarship" (Takeshita, 1997). Statements in the text given as if they were direct quotes may not in fact be so and there is a lack of awareness of the seriousness of being accurate and responsible for the evidence presented, according to western academic writing conventions. Takeshita's comment reflects his view that Japanese learners are exposed to a lack of training and low standards in the educational system (see also Liebman, 1992).

Thirdly, where students have had the experience of being taught how to write in English, what they may have done tends to consist of their keeping a journal, writing letters, or essays about their own opinions, ideas, or own experiences. There is no need to cite sources as they are not asked to integrate information from outside sources of information. Here is an example of one student at Tokyo University commenting on what he is learning in a new writing course taught by a practicing journalist (Asahi Evening News, 1997):

Suzuki, a second year liberal arts student at Tokyo University, says: "I passed my university entrance exam by getting good marks for writing a short essay, but that was just me writing what I wanted to about what I thought. For this (new course), I had to leave my own feelings out of it and write stories using what other people said. It was difficult. I'm not sure I did it all that well."

Given that English writing classes in high school consist of vocabulary and grammar exercises and translation from Japanese into English (Takeuchi, 1997), the need to show agency, that is, attribute the source of the ideas and opinions, does not arise and the use of a variety of reporting verbs or adverbial phrases, such as "according to" is not part of the lessons. Even more important in the present context, pupils are not taught that copying from a source is unacceptable.

Fourthly, still other problems need to be addressed if these issues are to be taken seriously. Motivation (see Grabe \& Kaplan, 1996) has to be considered; it is likely that only university level EFL learners who have strong professional and academic aspirations will be willing to spend the time to develop their writing skills. Fifthly, Japanese universities show a great deal of tolerance even when students are caught plagiarizing; the 
28

sanctions rarely involve expulsion or even a failing grade. Where nonJapanese teaching staff insist on a more rigorous approach, they may be accused of "Japan-bashing" as if they were claiming that Japanese learners are immoral. In conjunction with the Japanese university reactions, there are different views and degrees of awareness as well of what constitutes "academic writing" and, by extension, plagiarism amongst both NS and NNS teachers of English as a foreign language. Moreover, many may be unwilling to act as "police persons" and turn a blind eye to what evidence may be present.

\section{Conclusions}

The cultural explanation, which suggests that learners plagiarize due to their having been taught in primary and secondary schools that they can or even should just copy from an authority, a view of education said to be Confucian in origin, does not seem to be a sole viable interpretation in the context of Japan, at least not with the learners who are currently in the educational system. Certainly since World War II, the Japanese educational system has not actively promoted that point of view. In fact, to insist on this cultural interpretation may lead to the person being accused of cultural imperialism. Future research should rather consider underlying, unexamined cultural values regarding the degree of tolerance of cheating in general, plagiarism being just one example or manifestation, with others being copyright infringement and the pirating of such goods as CDs. Moreover, our study has shown that tertiary level students, perhaps world wide, may be more motivated by on-line concerns such as time pressures to get an assignment done (Spack, 1997).

However, we must ask ourselves what can be done with that information. Does one conclude that, on the argument of cultural relativism, it is permissible to plagiarize in the name of respect for another culture? Is cultural relativism acceptable in this context? It would be more fruitful to consider the reasons writing is not taught to the students in the junior and senior high schools in Japan. Perhaps this practice reflects the fact that, before WWII, only the elite were educated beyond the primary schools and it was assumed those students did not need to be taught to write. Note that, since that period of history, with virtually universal education at the junior and senior high school level in Japan, the curriculum has not yet acknowledged the need to teach basic academic skills such as writing; 
the educational system's main aims appear to be inculcating content and socialization into the Japanese sociocultural system. The issues are complex; classroom teachers, as must be acknowledged, cannot wait for further research as they are on, so to speak, "the front lines." We turn now to address teaching practices.

\section{Implications for Teachers}

As teachers of English as a second/foreign language, we have to decide what we can do to handle the situation. We suggest that we help the students who want to or need to do academic writing in English in some of the following ways.

First, we would maintain rigorous standards both for native and nonnative speakers of English for all international academic research and writing. Needless to say, this is not unproblematic; the degrees of copying found in essays and research reports confront the teacher with difficult decisions to make. It is clearly easier to recognize plagiarism in the second language writing of most learners for the reasons cited above. However, there are two particularly insidious contexts. The first concerns the students who have been abroad for part of their schooling and who consequently acquire English to varying degrees of proficiency. The teacher may not be able to judge with confidence to what extent an essay is plagiarized, especially in large size classes where it is difficult to know an individual student's ability to use the language. In the second context, an academic paper may be virtually nothing more than translated passages from the L1 into English; even though the translation is poorly done, thus appearing to be the learner's own writing, the teacher is likely to be at a loss as to how to proceed in this situation.

Second, with regard to the NNS learners, much more time to learn and practice the conventions of academic writing is necessary to develop the skills to any degree of fluency and success. Writing for EFL learners has to be viewed more from a developmental perspective, such that incremental stages are articulated, with learners being given extensive practice at each stage to build their skills and awareness of academic writing. Writing classes must provide sufficient time for learning the genres of writing which require the integration and synthesis of sources and citation norms. A first year student at the university where we collected our data is exposed to some genres, such as essay exams, which don't 
30

require references, and others which do, typically the research or term papers. The students need to be taught the differences (Chenoweth, 1997). In addition, we need to look more carefully at the correlation of language proficiency level and writing subskills. If we consider that students from a typical Japanese high school enter university with having had only the types of lessons described above, and, once in a typical Japanese university, with no writing classes provided, it is not surprising that the enormous gap becomes blatantly apparent and almost overwhelming in considering the means to address it within one academic year.

In addition to requiring more time and more practice to develop their writing skills, EFL learners cannot be taught academic writing based on assumptions that their problems are the same as those of L1 writing students. Most NNSs are being given instruction in writing drawing on research and practices from L1 writing teaching. Even with the highest motivation, a learner who still has a poor command of English will not be able to understand the instructions of the English teacher about how, for example, to write a summary or to integrate information from three sources into an essay on the environment. Consequently, insufficient or inappropriate teaching may explain to a great extent the situation.

Third, following Smith's (1997) stance that gate keeping with regards to disciplining students for plagiarism is unavoidable, explicit pedagogical intervention may be needed. A booklet entitled "Plagiarism and how to avoid it," by Gardner (1995), written to support a three-hour workshop on the subject, is an excellent example of the kind of effort to address the subject of plagiarism directly, rather than the ostrich-in-the-sand approach more commonly found. Learners are more able to understand the parameters and may welcome the directness to the reprimands and sanctions imposed on essays and papers only after they have been produced.

Finally, and risking treading into sensitive territory, it has to be acknowledged that ESL/EFL teachers need to be properly trained in helping learners develop their writing skills. This can be a difficult task when confronted with even the most willing learner. Further, teachers need to become more aware of the role of the previous educational systems. If learners have been largely expected to memorize whatever the teacher presents, in the form of texts and teachers' notes on a blackboard, and to repeat that information back on tests, it is not surprising 
they would not understand the gravity with which plagiarism is regarded within the western-influenced academic writing conventions. Consequently, in everyday classroom practices, it behooves the writing teacher of NNS learners to become more aware of the L1 cultural and educational background as well as the textual practices which the students bring with them in order to help them become bicultural academic writers.

\section{Works Cited}

Anderson, F. E. (1995). Classroom discourse and language socialization in a Japanese elementary-school setting: An ethnographic-linguistic study. University of Hawaii doctoral dissertation in linguistics. Ann Arbor: UMI Dissertation Services, Document \#9604132.

Applebome, P. (1997, June 9). Alarm in academia as term papers flood net. International Herald Tribune, pp. 1, 7.

Atkinson, D. \& Ramanathan, V. (1995). Cultures of writing: An ethnographic comparison of L1 and L2 university writing / language programs. TESOL Quarterly 29 (3), 539568.

Belcher, D. \& Braine, G. (Eds). (1995). Academic writing in as a second language: Essays on research and pedagogy. Norwood, NJ: Ablex.

Besnier, N. (1993). Reported speech and affect on Nukulaelae atoll. In J.H. Hill \& J. T. Irvine (Eds.), Responsibility and evidence in oral discourse 161-181. Cambridge: Cambridge University Press.

Bloch, J. \& Chi, L. (1995). A comparison of the use of citations in Chinese and English academic discourse. In D. Belcher \& G. Braine (Eds.), Academic writing in a second language: Essays on research and pedagogy. Norwood, NJ: Ablex. 231-274.

Braine, G. Writing in the natural sciences and engineering. In D. Belcher \& G. Braine (Eds.), Academic writing in a second language: Essays on research and pedagogy. Norwood, NJ: Ablex. 113-134.

Brown, G. (1997). Personal communication.

Campbell, C. (1990). Writing with others' words: Using background reading text in academic compositions. In B. Kroll (Ed.), Second language writing.Cambridge: Cambridge University Press 221-230.

Chenoweth, A. (1997). Personal communication.

Clark, J.L. 1987. Curriculum renewal in school foreign language learning. Oxford: Oxford University Press.

Connor, U. M. \& Kramer, M. G. Writing from sources: Case studies of graduate students in business management. In D. Belcher \& G. Braine (Eds.), Academic writing in a second language: Essays on research and pedagogy. Norwood, NJ: Ablex 155-182. 


\section{2}

Gardner, D. (1995). Plagiarism and how to avoid it. Hong Kong: The University of Hong Kong.

Hinkel, E. (2000). The goals and the politics of L2 writing instruction. TESOL Matters $10(2), 12$.

Hinkel, E. (1995). Native and nonnative speakers' pragmatic interpretations of English texts. TESOL Quarterly 28 (2), 353-376.

Howard, R. M. (1995). Plagiarisms, authorships, and the academic death penality. College English 57 (7), 788-806.

Lakoff, G. \& Johnson, M. (1980). Metaphors we live by. Chicago: University of Chicago Press.

Liebman, J.D. (1992). Toward a new contrastive rhetoric: Differences between Arabic and Japanese rhetorical instruction. Journal of Second Language Writing 1 (2), 141165.

Leki, I. \& Carson, J. (1997). Completely different worlds: EAP and the writing experiences of ESL students in university courses. TESOL Quarterly 31(1), 39-70.

LoCastro, V. \& Netsu, M. (1997). “ to omoimasu and "I think:” A pragmatic mismatch with academic skills consequences.” Paper presented at TESOL'97, Orlando, Florida, 11-14 March.

Matalene, C. (1985). Contrastive rhetoric: An American writing teacher in China. College English 47, 789-808.

New Horizon: English Writing (1994). Tokyo: Tokyo Shoseki.

Pennycook, A. (1996). Borrowing others' words: Text, ownership, memory, and plagiarism. TESOL Quarterly 30 (2), 201-230.

Sasaki, M. (1997). Personal communication.

Scollon, R. (1994). As a matter of face: The changing ideology of authorship and responsibility in discourse. World Englishes 13, 33-46.

Scollon, R. (1995a). From sentence to discourses; ethnography to Ethnographic: Conflicting trends in TESOL research. TESOL Quarterly 29 (3), 381-384.

Scollon, R. (1995b). Plagiarism and ideology: Identity in intercultural discourse. Language in Society 24, 1-28.

Smith, J. (1997). Students' goals, gatekeeping, and some questions of ethics. College English 59 (3), 299-320.

Spack, L. (1997). The acquisition of academic literacy in a second language. Written Communication 14 (1), 3-62.

Swales, J.M. \& Feak, C.B. (1994). Academic writing for graduate students: Essential tasks and skills. Ann Arbor: University of Michigan Press.

Taylor, G. \& Chen, T. (1991). Linguistic, cultural and subcultural issues in contrastive discourse analysis: Anglo-American and Chinese scientific texts. Applied Linguistics 12 (3), 319-336. 
Takeuchi, H. (1997). On improving high school students' writing ability. Nanzan Studies in English Language Education 4, 53-78. 
34

APPENDIXA: Questionnaire

\section{QUESTIONNAIRE ON ACADEMIC WRITING}

\section{Part I}

1. When you were a freshman or sophomore, did you do any of the ELP writing courses? If so, circle each which applies.

$\begin{array}{llll}\text { 1st year WR } & \text { spring } & \text { fall } & \text { winter } \\ \text { 2nd year } & \text { Theme writing } & & \end{array}$

2. What grades did you get? Write in the grade you got for each.

1st year WR

$$
\text { Spring Fall Winter }
$$

2nd Theme writing

3. If you did not do the ELP writing courses, describe what training you did get and where in writing academic papers.

4. Generally, what are your feelings about having to write academic papers in English at ICU? Put a check in front of as many as you feel describe your feelings.

_ Necessary to fulfill requirements for graduation at ICU.

_ Useful training for my future career or work.

_ Interesting to learn a different way of thinking.

_ Uncomfortable for me.

_ I cannot write what I'm really thinking in English.

_ English is imposed on us.

- I can't understand the writing style of a different culture or way of thinking.

_ I want to learn how to write well in Japanese.

— Writing in such a style is only required in courses done in English.

_ Necessary for writing my senior thesis.

_ If I can write well in Japanese, it does not matter how I write in English.

_ I came to ICU to improve my English ability in all ways.

— ICU should not have such requirements as it is a university in Japan. 


\section{Part II}

1. Please write what you think plagiarism is. (Please feel free to write in Japanese.)

2. Have you ever plagiarized on your assignments in any of your courses at ICU? never sometimes often many times

3. If you have plagiarized, in which course(s)?

$\mathrm{Wr}$

Theme Writing

Other courses which require papers done in English

On take-home tests

Senior/M.A. thesis

Exams held in class

Course which require papers in Japanese.

Other:

4. From the list below, select as many items as you feel describe your situation when you plagiarized. Put a check in front of those which apply to you.

_ I copied my essay entirely from a library or other outside source.

_ I copied my essay entirely from another student's essay.

_ I copied parts of my essay from a variety of sources.

_ Most of my essay came from Japanese sources which I translated into English, without citing the sources.

_ I only copied some sentences/paragraphs.

_ I copied whenever I was not able to paraphrase well from the original source.

5. Now, from the list below, choose as many which describe your feelings when you plagiarized. Put a check in front of those which apply to you.

_ I knew what I was doing, but as so many other students do it, I just hoped I'd get away with it as well.

_ I knew my essay was poor, so I plagiarised in order to improve it and get a better grade.

_ I ran out of time; I didn't have enough time to do the essay myself.

_ I really don't understand how to do academic writing in English.

_ I didn't make proper note cards or take down good notes in the library, so I didn't have the information to cite my sources correctly; I forgot where I found the material.

I didn't think the instructor or professor would notice when students plagiarize. 


\section{6}

- I believe many instructors/professors don't really care about whether or not students plagiarize.

_ I think a lot of professors and instructors don't read our essays and papers carefully enough to know whether or not we plagiarize.

_ I never had to worry about plagiarizing in high school.

- If I paraphrase what the author of the original source wrote, then I will make mistakes and get a bad grade.

- If I have an idea which is the same as the idea of the author of the outside source, I don't understand the reason I have to cite the author: it's my idea too.

_ I only cite when I quote directly; otherwise, I do not say where the ideas I use come from.

_ I take ideas and words from several different sources, put them together, and just use them without saying where they come from.

_ In the ELP I can't use Japanese sources; so I just translate from them and don't say where the ideas came from.

_ I feel frustrated when I have to write an essay and do nothing but cite what other people have said. I am not allowed to give my own ideas or opinions.

I I have no confidence in my ability to write good papers in English.

_ I am disappointed in the way I was taught to write in English.

_ I don't really care; I just want to pass.

_ In Japanese academic writing, it's OK if I plagiarise.

_ I find writing where I have to cite sources very boring.

_ Instructors and professors don't usually say where their ideas come from: why do we have to do so?

Part III

Bio-data

1. What year are you in? 1st 2nd 3rd 4th 5th ?

2. $\mathrm{M} \mathrm{F}$

3. Division:

3. Have you ever been caught copying or plagiarizing at ICU?

4. What happened then?

\section{WRITE ANY COMMENTS OR REACTIONS YOU MAY HAVE}


APPENDIX B: RESULTS OF RELEVANT QUESTIONS

$($ Total $=37)$

\begin{tabular}{lr|lr}
\hline Stage of study & & Division (Faculty) & \\
\hline First year undergraduates & 8 & Languages & 15 \\
Second year undergraduates & 8 & Natural Sciences & 14 \\
Third year undergraduates & 15 & Education & 5 \\
Fourth year undergraduates & 4 & International Studies & 1 \\
First-year MA students & 1 & Social Sciences & 1 \\
[Unspecified & 1 ] & [Unspecified & 1 ] \\
\hline
\end{tabular}

Table 1: Demographic information

\begin{tabular}{lrrrr}
\hline How often have you plagiarised? & Often & sometimes & never & Total \\
\hline Natural science major course (Total =12) & 1 & 7 & 4 & 12 \\
Introductory linguistics course (Total 14) & 1 & 8 & 5 & 14 \\
Intermediate linguistics course (Total =11) & 0 & 5 & 6 & 11 \\
All & 2 & 20 & 15 & 37 \\
\hline
\end{tabular}

Table 2 Frequency of plagiarism (\%)

\begin{tabular}{ll}
\hline What happened? & \\
\hline Nothing & 1 \\
Warned & 1 \\
Rewrite & 1 \\
\hline
\end{tabular}

Table 3: consequences of plagiarism to students caught plagiarizing $($ Total $=3)$

\begin{tabular}{lc}
\hline Comment & Number making this comment \\
\hline Useful training for my future career or work & 30 \\
Necessary to fulfill requirements at ICU & 22 \\
Writing in such a style is only required in courses done in & 19 \\
$\quad$ English & 19 \\
I want to learn how to write well in Japanese. & 14 \\
Interesting to learn a different way of thinking.
\end{tabular}

Table 4: Perceived value of academic writing 
Courses which require papers in Japanese

Other courses (i.e. outside the English Language Program)

which require papers done in English

Exams held in class

Theme writing (second year course in ELP)

On take-home tests

ELP writing classes (first year)

Table 5 Contexts of plagiarism

I only copied some sentences/paragraphs.

I copied whenever I was not able to paraphrase well from the original source.

I copied parts of my essay from a variety of sources.

Table 6: reported extent of plagiarism

I take ideas and words from several different sources, put them together, and just use

them without saying where they come from.

If I have an idea which is the same as the idea of the author of the outside source, I 9

don't understand the reason I have to cite the author; it's my idea, too.

I ran out of time; I didn't have enough time to do the essay myself.

I think a lot of professors and instructors don't read our essays and papers carefully 4 enough to know whether or not we plagiarize.

Table 7 Reported circumstances of plagiarism 